\title{
DECISION-MAKING UNDER RISK AND UNCERTAINTY AND ITS APPLICATION IN STRATEGIC MANAGEMENT
}

\author{
José M. MERIGÓ \\ Department of Business Administration, University of Barcelona, \\ Av. Diagonal 690, 08034 Barcelona, Spain \\ Manchester Business School, University of Manchester, Booth Street West, \\ M156PB Manchester, UK \\ E-mail: jmerigo@ub.edu
}

Received 08 November 2011; accepted 25 January 2012

\begin{abstract}
We introduce a new decision-making model that unifies risk and uncertain environments in the same formulation. For doing so, we present the induced probabilistic ordered weighted averaging (IPOWA) operator. It is an aggregation operator that unifies the probability with the OWA operator in the same formulation and considering the degree of importance of each concept in the aggregation. Moreover, it also uses induced aggregation operators that provide a more general representation of the attitudinal character of the decision-maker. We study its applicability and we see that it is very broad because all the previous studies that use the probability or the OWA operator can be revised and extended with this new approach. We briefly analyze some basic applications in statistics such as the implementation of this approach with the variance, the covariance, the Pearson coefficient and in a simple linear regression model. We focus on a multi-person decision-making problem in strategic management. Thus, we are able to construct a new aggregation operator that we call the multi-person IPOWA operator. Its main advantage is that it can deal with the opinion of several persons in the analysis so we can represent the information in a more complete way.
\end{abstract}

Keywords: OWA operator, probabilities, induced aggregation operators, uncertainty, multi-person decision-making, strategic management.

JEL Classification: C44, C49, D81, D89.

\section{Introduction}

Decision-making problems are very common in our lifes. In business and economics, people are always making decisions. Sometimes, these decisions are very relevant because they involve huge amounts of money (macro decisions) and sometimes they simply represent a simple action with almost no cost (micro decisions). In our economy, the politicians make macroeconomic decisions that require a lot of efforts in order to be properly assessed. At the same time, we can also find microeconomic decisions made by an individual consumer when dealing with the usual actions of his life like the decision 
of selecting an apartment or a car, or more simply the selection of a product in a supermarket. Therefore, it is clear that decision processes are always present in our World. Moreover, we can find more complex decisions based on our intuition or on the nature of the universe we are living in such as the unconsciousness decisions people are making when selecting the appropriate words when having a conversation with other people.

Usually, these decisions are made with the intuition and with some partial information people have. However, implicitly there is a mathematical (or statistical) model that represents the problem that should be able to provide the optimal decision according to the interests of the decision-maker. Sometimes, our intuition finds this decision but sometimes not. In this context, through decades, scientists have been looking for the optimal model for making decisions. Unfortunately, our world is strongly affected by different types of uncertainty. Therefore, it is not easy to find the optimal choice because in a lot of problems the decisions are made under uncertainty.

In the literature, we find a wide range of decision-making models that consider different environments, scenarios and concepts (Zavadskas, Turskis 2010; Zavadskas et al. 2010). Some of them have focussed on decision-making under risk environments (Merigó et al. 2013; Belles et al. 2013; Yager 1992, 1999, 2009). That is, when we have some kind of uncertainty but we can assess it with probabilistic information. Thus, we are using probabilistic aggregation operators in the analysis (Merigó 2010). Some others have analyzed decision-making under uncertainty. That is, when we can not assess the uncertainty with probabilities. Therefore, we have to use more subjective methods such as the use of the ordered weighted averaging (OWA) operator (Yager 1988). It is an aggregation operator that provides a parameterized family of aggregation operators between the minimum and the maximum. It unifies the classical decision-making methods under uncertainty (optimistic criteria, Wald, Laplace and Hurwicz (Luce, Raiffa 1989)) in one single formulation that includes these methods as particular cases of a more general framework. Since its appearance, the OWA operator has been studied by a lot of authors (Beliakov et al. 2007; Chang, Wen 2010; Wei 2010a; Yager, Kacprzyk 1997; Zhou, Chen 2010; Zhou et al. 2012).

An interesting extension of the OWA operator is the induced OWA (IOWA) operator (Yager, Filev 1999). It provides a more general reordering process of the information to be aggregated by using order inducing variables. Thus, we can consider more complex attitudinal characters that include psychological and personal factors in the analysis. Recently, Merigó and Gil-Lafuente (2009) have presented the induced generalized OWA (IGOWA) operator that generalizes the IOWA operator by using generalized and quasi-arithmetic means. Wei $(2010 \mathrm{~b}, 2010 \mathrm{c})$ considered the use of different types of fuzzy information and harmonic means. Merigó and Casanovas (2010a, 2011a, 2011b), Zeng and $\mathrm{Su}$ (2012) also considered the use of imprecise information in the analysis. They also considered the use of distance measures and heavy aggregations (Merigó, Casanovas 2010b, 2011c; Merigo et al. 2014).

Another interesting generalization is the probabilistic OWA (POWA) operator (Merigó 2012; Merigó, Wei 2011). It unifies the probability and the OWA operator considering 
the degree of importance that each concept has in the aggregation. It is worth noting that in the literature we find some previous studies that presented different ways for unifying these concepts such as the immediate probability (Engemann et al. 1996; Yager et al. 1995). Moreover, some other models focussed on the unification between the weighted average and the OWA operator such as the hybrid average (Xu, Da 2003) and the weighted OWA operator (Torra 1997). However, it is easy to use the weighted average as a probability. Therefore, it is straightforward to extend these models in a probabilistic framework. However, only the POWA operator is able to consider the degree of relevance of each concept in the analysis.

The objective of this paper is to present a new approach for dealing with risk and uncertain environments in the same formulation. For doing so, first, we present the induced probabilistic OWA (IPOWA) operator. It is an aggregation operator that unifies the probability and the IOWA operator in the same formulation and considering the degree of importance of each concept in the aggregation. Moreover, it provides a parameterized family of aggregation operators between the minimum and the maximum. Furthermore, it also considers complex reordering processes that permit to assess complex attitudinal characters of the decision-maker. It includes a wide range of particular cases including the maximum, the minimum, the arithmetic mean, the probabilistic maximum, the probabilistic minimum, the probabilistic aggregation, the OWA operator, the IOWA operator and the POWA operator.

We study the applicability of this approach and we see that it is very broad because all the previous studies the use the probability and the OWA operator can be revised and extended with this new approach. Moreover, in case the classical approach is enough, we can always reduce the new model to the classical one because it is included as a particular case. Thus, we can see that we can extend this approach in statistics and in all the disciplines that use statistical techniques based on the probability and the OWA operator such as decision theory, economics, soft computing, engineering and physics. We briefly present some basic examples in statistics by using the IPOWA operator in the variance, the covariance, the Pearson coefficient and in a simple linear regression model.

With this approach we can unify decision-making problems under risk and under uncertainty in the same formulation and considering the degree of importance that each approach has in the specific problem considered. Thus, we can provide a more general framework for decision-making. We also study some other approaches based on the use of "ex-ante" and "ex-post" decisions and situations with imprecise information. We focus on a multi-person decision-making problem in strategic management regarding the selection of the optimal strategy for a company. By using a multi-person analysis, we obtain the multi-person IPOWA (MP-IPOWA) operator. It is an aggregation operator with similar properties than the IPOWA operator that can assess the opinion of several persons in the analysis. We see that it includes a wide range of particular cases such as the multi-person probabilistic aggregation (MP-PA) and the multi-person 
IOWA (MP-IOWA) operator. The application in strategic management shows that the decision-maker gets a better representation of the problem because he can assess risk and uncertain environments in the same formulation and select the alternative in closest accordance with his interests. Note that strategic management problems are a key issue in decision-making because we can formulate strategies in different fields. Especially, in business decision-making it is very useful because the enterprises need to formulate the optimal strategies in order to success in the development of the company.

This paper is organized as follows. In Section 1 we briefly review some basic concepts regarding the OWA, the IOWA and the POWA operator. Section 2 presents the IPOWA operator and Section 3 analyzes a wide range of families. In Section 4 we analyze the applicability of the IPOWA operator and in Section 5 the application of multi-person decision-making problems in strategic management. In the last Section we summarize the main conclusions of the paper.

\section{Preliminaries}

In this Section, we briefly describe the OWA operator, the IOWA operator and the POWA operator.

\subsection{The OWA operator}

The OWA operator (Yager 1988) is an aggregation operator that provides a parameterized family of aggregation operators between the minimum and the maximum. It can be defined as follows.

Definition 1: An OWA operator of dimension $n$ is a mapping $O W A: R^{n} \rightarrow R$ that has an associated weighting vector $W$ of dimension $n$ such that $w_{j} \in[0,1]$ and $\sum_{j=1}^{n} w_{j}=1$, then:

$$
O W A\left(a_{1}, \ldots, a_{n}\right)=\sum_{j=1}^{n} w_{j} b_{j},
$$

where $b_{j}$ is the $j$ th largest of the $a_{i}$.

One of the key aspects of the OWA operator in decision-making under uncertainty is that it unifies the classical decision-making methods in one single formulation. Thus, the optimistic criteria, the pessimistic (or Wald) criteria, the Laplace criteria and the Hurwicz criteria are particular cases of the OWA operator. With the OWA operator, the optimistic criteria is found if $w_{1}=1$ and $w_{j}=0$ for all $j \neq 1$. The pessimistic criteria if $w_{n}=1$ and $w_{j}=0$ for all $j \neq n$. The Laplace criteria if $w_{j}=1 / n$ for all $j$. Finally, the Hurwicz criteria is found if $w_{1}=\alpha, w_{n}=1-\alpha$, and $w_{j}=0$ for all $j \neq 1, n$.

Note that different properties can be studied such as the distinction between descending and ascending orders, different measures for characterizing the weighting vector and other families of OWA operators. For further reading, see Merigó and Casanovas (2011a), Merigó and Yager (2013), Yager et al. (2011), and Zhao et al. (2010). 


\subsection{The induced OWA operator}

The IOWA operator was introduced by Yager and Filev (1999) and it represents an extension of the OWA operator. Its main difference is that the reordering step is not developed with the values of the arguments $a_{i}$. In this case, the reordering step is developed with order inducing variables. The IOWA operator also includes as particular cases the maximum, the minimum and the average criteria. It can be defined as follows.

Definition 2: An IOWA operator of dimension $n$ is a mapping IOWA: $R^{n} \times R^{n} \rightarrow R$ that has an associated weighting vector $W$ of dimension $n$ with $\sum_{j=1}^{n} w_{j}=1$ and $w_{j} \in[0,1]$, such that:

$$
\operatorname{IOWA}\left(\left\langle u_{1}, a_{1}\right\rangle,\left\langle u_{2}, a_{2}\right\rangle, \ldots,\left\langle u_{n}, a_{n}\right\rangle\right)=\sum_{j=1}^{n} w_{j} b_{j},
$$

where $b_{j}$ is the $a_{i}$ value of the IOWA pair $\left\langle u_{i}, a_{i}\right\rangle$ having the $j$ th largest $u_{i}, u_{i}$ is the orderinducing variable and $a_{i}$ is the argument variable.

Note that it is possible to distinguish between the descending IOWA (DIOWA) operator and the ascending IOWA (AIOWA) operator. The IOWA operator is also monotonic, bounded, idempotent and commutative. For further reading on the IOWA, see Merigó and Gil-Lafuente (2009, 2013), Merigó and Casanovas (2009), and Yager (2003).

\subsection{The probabilistic OWA operator}

The POWA operator is an aggregation operator that unifies the probability and the OWA operator in the same formulation considering the degree of importance that each concept has in the analysis and providing a parameterized family of aggregation operators between the minimum and the maximum (Merigó, Wei 2011; Merigó 2012; Zeng et al. 2013). It is defined as follows.

Definition 3: A POWA operator of dimension $n$ is a mapping POWA: $R^{n} \rightarrow R$ that has an associated weighting vector $W$ of dimension $n$ such that $w_{j} \in[0,1]$ and $\sum_{j=1}^{n} w_{j}=1$, according to the following formula:

$$
\operatorname{POWA}\left(a_{1}, a_{2}, \ldots, a_{n}\right)=\sum_{j=1}^{n} \hat{p}_{j} b_{j},
$$

where $b_{j}$ is the $j$ th largest of the $a_{i}$, each argument $a_{i}$ has an associated probability $p_{i}$ with $\sum_{i=1}^{n} p_{i}=1$ and $p_{i} \in[0,1], \hat{p}_{j}=\beta w_{j}+(1-\beta) p_{j}$ with $\beta \in[0,1]$ and $p_{j}$ is the probability $p_{i}$ ordered according to $b_{j}$, that is, according to the $j$ th largest of the $a_{i}$.

By choosing a different manifestation in the weighting vector, we are able to obtain a wide range of particular types of POWA operators (Merigó, Wei 2011). Especially, when $\beta=0$, we get the probabilistic aggregation, and if $\beta=1$, we get the OWA operator.

\section{The induced probabilistic OWA operator}

The induced probabilistic OWA (IPOWA) operator is an aggregation operator that uses probabilities and OWAs in the same formulation. It also uses order inducing variables in order to represent the reordering process from a general point of view. Its main advan- 
tage is that it can unify the probability and the IOWA operator in the same formulation and considering the degree of importance of each concept in the aggregation. Thus, we can use the objective information of the problem and the attitudinal character of the decision maker in the same formulation. It can be defined as follows.

Definition 4: An IPOWA operator of dimension $n$ is a mapping IPOWA: $R^{n} \times R^{n} \rightarrow R$ that has an associated weighting vector $W$ of dimension $n$ such that $w_{j} \in[0,1]$ and $\sum_{j=1}^{n} w_{j}=1$, then:

$$
\text { IPOWA }\left(\left\langle u_{1}, a_{1}\right\rangle,\left\langle u_{2}, a_{2}\right\rangle, \ldots,\left\langle u_{n}, a_{n}\right\rangle\right)=\sum_{j=1}^{n} \hat{p}_{j} b_{j},
$$

where $b_{j}$ is the $a_{i}$ value of the IPOWA pair $\left\langle u_{i}, a_{i}\right\rangle$ having the $j$ th largest $u_{i}, u_{i}$ is the order inducing variable, each argument $a_{i}$ has an associated probability $p_{i}$ with $\sum_{i=1}^{n} p_{i}=1$ and $p_{i} \in[0,1], \hat{p}_{j}=\beta w_{j}+(1-\beta) p_{j}$ with $\beta \in[0,1]$ and $p_{j}$ is the probability $p_{i}$ ordered according to $b_{j}$, that is, according to the $j$ th largest $u_{i}$.

Note that it is also possible to formulate the IPOWA operator separating the part that affects the IOWA operator and the part that affects the probabilities. Thus, we get the following.

Definition 5: An IPOWA operator is a mapping IPOWA: $R^{n} \times R^{n} \rightarrow R$ of dimension $n$, if it has associated a weighting vector $W$, with $\sum_{j=1}^{n} w_{j}=1$ and $w_{j} \in[0,1]$ and a probabilistic vector $P$, with $\sum_{i=1}^{n} p_{i}=1$ and $p_{i} \in[0,1]$, such that:

$$
\text { IPOWA }\left(\left\langle u_{1}, a_{1}\right\rangle,\left\langle u_{2}, a_{2}\right\rangle, \ldots,\left\langle u_{n}, a_{n}\right\rangle\right)=\beta \sum_{j=1}^{n} w_{j} b_{j}+(1-\beta) \sum_{i=1}^{n} p_{i} a_{i},
$$

where $b_{j}$ is the $a_{i}$ value of the IPOWA pair $\left\langle u_{i}, a_{i}\right\rangle$ having the $j$ th largest $u_{i}, u_{i}$ is the order inducing variable and $\beta \in[0,1]$.

Note that if $\beta=1$, we get the IOWA operator and if $\beta=0$, the probabilistic aggregation. Note also that if $w_{j}=1 / n$ and $p_{i}=1 / n$, for all $i$ and $j$, then, the IPOWA becomes the usual arithmetic mean.

Example 1: Assume the following arguments in an aggregation process: 70, 40, 30, 50, 60 and the order inducing variables $U=(24,39,32,26,13)$. Assume the following weighting vector $W=(0.1,0.1,0.2,0.3,0.3)$ and the following probabilistic weighting vector $P=(0.4,0.3,0.1,0.1,0.1)$. Note that the probabilistic information has a degree of importance of $70 \%$ while the OWA a degree of $30 \%$. If we want to aggregate this information by using the IPOWA operator, we get the following. With Eq. (4) we calculate the new weighting vector as:

$$
\begin{gathered}
\hat{v}_{1}=0.3 \times 0.1+0.7 \times 0.3=0.24, \hat{v}_{2}=0.3 \times 0.1+0.7 \times 0.1=0.1, \\
\hat{v}_{3}=0.3 \times 0.2+0.7 \times 0.1=0.13, \hat{v}_{4}=0.3 \times 0.3+0.7 \times 0.4=0.37, \\
\hat{v}_{5}=0.3 \times 0.3+0.7 \times 0.1=0.16 .
\end{gathered}
$$


And then, we calculate the aggregation process as follows:

$$
I P O W A=0.24 \times 40+0.1 \times 30+0.13 \times 50+0.37 \times 70+0.16 \times 60=54.6 .
$$

With Eq. (5), we aggregate as follows:

$$
\begin{aligned}
& I P O W A=0.3 \times(0.1 \times 40+0.1 \times 30+0.2 \times 50+0.3 \times 70+0.3 \times 60)+ \\
& 0.7 \times(0.4 \times 70+0.3 \times 40+0.1 \times 30+0.1 \times 50+0.1 \times 60)=54.6 .
\end{aligned}
$$

Obviously, we get the same results with both formulas.

Note that if the weighting vector of the OWA or the probability is not normalized, i.e. $W=\sum_{j=1}^{n} w_{j} \neq 1$, or $P=\sum_{i=1}^{n} p_{i} \neq 1$ then, the IPOWA operator can be expressed as:

$$
\text { IPOWA }\left(\left\langle u_{1}, a_{1}\right\rangle,\left\langle u_{2}, a_{2}\right\rangle, \ldots,\left\langle u_{n}, a_{n}\right\rangle\right)=\frac{1}{W} \sum_{j=1}^{n} w_{j} b_{j}+\frac{1}{P} \sum_{i=1}^{n} p_{i} a_{i} .
$$

The IPOWA is monotonic, bounded and idempotent. Note that it is possible to distinguish between the descending IPOWA (DIPOWA) and the ascending IPOWA (AIPOWA) operator by using $w_{j}=w^{*}{ }_{n-j+1}$, where $w_{j}$ is the $j$ th weight of the DIPOWA and $w^{*}{ }_{n-j+1}$ the $j$ th weight of the AIPOWA operator.

Note that in the literature we may find other models that deal with probabilities and OWA operators in the same formulation. The main approach is the concept of immediate probability (Engemann et al. 1996; Merigó 2010; Yager et al. 1995; Yager 1999). Its main disadvantage is that it can not represent the degree of importance of each concept in the aggregation process. In the following, we briefly present its definition when using induced aggregation operators. Thus, we obtain the induced immediate probabilistic OWA (IP-IOWA) operator.

Definition 6: An IPIOWA operator of dimension $n$ is a mapping IPIOWA: $R^{n} \times R^{n} \rightarrow R$ that has associated a weighting vector $W$ of dimension $n$ such that $w_{j} \in[0,1]$ and $\sum_{j=1}^{n} w_{j}=1$, according to the following formula:

$$
\text { IPOWA }\left(\left\langle u_{1}, a_{1}\right\rangle,\left\langle u_{2}, a_{2}\right\rangle, \ldots,\left\langle u_{n}, a_{n}\right\rangle\right)=\sum_{j=1}^{n} \hat{p}_{j} b_{j},
$$

where $b_{j}$ is the $a_{i}$ value of the IPIOWA pair $\left\langle u_{i}, a_{i}\right\rangle$ having the $j$ th largest $u_{i}$, $u_{i}$ is the order inducing variable, each $a_{i}$ has associated a probability $p_{i}$ with $\sum_{i=1}^{n} p_{i}=1$ and $p_{i} \in[0,1], \hat{p}_{j}=\left(w_{j} p_{j} / \sum_{j=1}^{n} w_{j} p_{j}\right)$ and $p_{j}$ is the probability $p_{i}$ ordered according to $b_{j}$, that is, according to the $j$ th largest $u_{i}$.

Note that other approaches that could be taken into account are the hybrid averaging (HA) (Xu, Da 2003) and the weighed OWA (WOWA) operator (Torra 1997). These models unify the OWA operator with the weighted average (WA). Therefore, they can also be extended for situations with the OWA operator and probabilities assuming that for some situations the WA can be seen as a probability. However, these and other approaches are useful for some particular situations but they do not seem to be so complete than the IPOWA because they cannot unify them considering different degrees of importance to each case. 


\section{Families of IPOWA operators}

By using a different manifestation in the weighting vector $W$ (or $P$ ) we can study a wide range of particular cases. Each case is a particular attitude of the decision maker that is useful in some specific situations. For example, we can form the probabilistic maximum, the probabilistic minimum, the arithmetic probabilistic aggregation (APA) and the arithmetic IOWA (A-IOWA) operator.

Remark 1: The probabilistic maximum is found when $w_{p}=1$ and $w_{j}=0$, for all $j \neq p$, and $u_{p}=\operatorname{Max}\left\{a_{i}\right\}$. The probabilistic minimum is formed when $w_{q}=1$ and $w_{j}=0$, for all $j \neq q$, and $u_{q}=\operatorname{Min}\left\{a_{i}\right\}$.

Remark 2: More generally, the step-IPOWA is formed when $w_{k}=1$ and $w_{j}=0$ for all $j \neq k$. Note that if $k=p$ and $u_{p}=\operatorname{Max}\left\{a_{i}\right\}$, the step-IPOWA becomes the probabilistic maximum. If $k=q$ and $u_{q}=\operatorname{Min}\left\{a_{i}\right\}$, the step-IPOWA becomes the probabilistic minimum operator.

Remark 3. The APA operator is obtained when $w_{j}=1 / n$ for all $j$. That is:

$$
A-P A\left(\left\langle u_{1}, a_{1}\right\rangle,\left\langle u_{2}, a_{2}\right\rangle, \ldots,\left\langle u_{n}, a_{n}\right\rangle\right)=\frac{1}{n} \beta a_{i}+(1-\beta) \sum_{i=1}^{n} p_{i} a_{i},
$$

Remark 4: The A-IOWA operator is formed when $p_{i}=1 / n$ for all $i$. In this case, we get:

$$
\text { A-IOWA }\left(\left\langle u_{1}, a_{1}\right\rangle,\left\langle u_{2}, a_{2}\right\rangle, \ldots,\left\langle u_{n}, a_{n}\right\rangle\right)=\beta \sum_{j=1}^{n} w_{j} b_{j}+(1-\beta) \frac{1}{n} a_{i} .
$$

Note that if $w_{p}=1$ and $w_{j}=0$, for all $j \neq p$, and $u_{p}=\operatorname{Max}\left\{a_{i}\right\}$, the A-IOWA operator becomes the A-Max that it is also known in the literature as the or-like S-IOWA operator and if $w_{q}=1$ and $w_{j}=0$, for all $j \neq q$, and $u_{q}=\operatorname{Min}\left\{a_{i}\right\}$, it becomes the A-Min that it is known as the and-like S-IOWA operator (Merigó, Gil-Lafuente 2009; Yager 1993).

Remark 5: Some other aggregations could be formed following the recent literature for obtaining OWA weights (Merigó, Gil-Lafuente 2009; Yager 1993). For example, we can consider the following particular cases:

- The arithmetic mean: if $w_{j}=1 / n$ for all $j$ and $p_{i}=1 / n$ for all $i$.

- The median-IPOWA: if $n$ is odd we assign $w_{(n+1) / 2}=1$ and $w_{j^{*}}=0$ for all others. If $n$ is even we assign for example, $w_{n / 2}=w_{(n / 2)+1}=0.5$ and $w_{j^{*}}=0$ for all others.

- The weighted median-IPOWA: we select the argument $b_{k}$ that has the $k$ th largest argument such that the sum of the weights from 1 to $k$ is equal or higher than 0.5 and the sum of the weights from 1 to $k-1$ is less than 0.5 .

- The olympic-IPOWA: when $w_{1}=w_{n}=0$, and for all others $w_{j^{*}}=1 /(n-2)$.

- The general olympic-IPOWA: if $w_{j}=0$ for $j=1,2, \ldots, k, n, n-1, \ldots, n-k+1$, and for all others $w_{j^{*}}=1 /(n-2 k)$, where $k<n / 2$.

- Centered-IPOWA: if it is symmetric, strongly decaying and inclusive. It is symmetric if $w_{j}=w_{j+n-1}$. It is strongly decaying when $i<j \leq(n+1) / 2$ then $w_{i}<w_{j}$ and when $i>j \geq(n+1) / 2$ then $w_{i}<w_{j}$. And it is inclusive if $w_{j}>0$. 
Remark 6: Other families of IPOWA operators could be studied by using them both in the probabilities and in the IOWA operator. Moreover, we can consider different types for each of case. Thus, we can consider a wide range of alternatives. In Table 1, we present some of these cases.

Table 1. Mixing families of probabilistic aggregations (PA) and IOWA operators

\begin{tabular}{|c|c|c|c|c|c|c|c|}
\hline \multirow{8}{*}{ Prob. } & \multicolumn{7}{|c|}{ IOWA } \\
\hline & & IOWA & Max & Min & AM & Step & Centered \\
\hline & $\mathrm{PA}$ & IPOWA & Max-PA & Min-PA & A-PA & Step-PA & Cent-PA \\
\hline & $\operatorname{Max}$ & IOWA-Max & Max & Min-Max & A-Max & Step-Max & Cent-Max \\
\hline & Min & IOWA-Min & Max-Min & Min & A-Min & Step-Min & Cent-Min \\
\hline & $\mathrm{AM}$ & IOWA-AM & Max-AM & Min-AM & $\mathrm{AM}$ & Step-AM & Cent-AM \\
\hline & Step & IOWA-Step & Max-Step & Min-Step & A-Step & Step & Cent-Step \\
\hline & Cent. & IOWA-Cent. & Max-Cent. & Min-Cent. & A-Cent. & Step-Cent. & Centered \\
\hline
\end{tabular}

\section{Applicability of the IPOWA operator}

\subsection{Introduction}

The IPOWA operator is applicable in a wide range of situations where it is possible to use probabilistic information and OWA operators. Therefore, we see that the applicability is incredibly broad because all the previous models, theories, etc., that use the probability (or the OWA) can be revised and extended by using the IPOWA operator.

Note that in case we believe that the classical model is enough, we can always reduce the IPOWA to the PA or the IOWA. Therefore, this new model always includes the classical approach. However, we believe that in the future there will be a need to produce various degrees of underestimated and overestimated results because they will provide more complete information in the analysis. Using the model presented in this paper, we can vary the degree of importance of these concepts depending on the particular problem we are analyzing. This will allow us to consider situations where the probability or the OWA is more relevant than the other concept. In the following, we mention some of the main research application areas. Within each field, there are many potential applications.

- Statistics: the IPOWA is a key instrument to revise the majority of the statistical sciences. For example, we can implement it in linear and multiple regressions. We can also extend it to probability theory and a lot of other related areas such as hypothesis testing and inference statistics.

- Fuzzy Set Theory and Soft Computing: all aspects of fuzzy set theory that use statistical techniques based on the PA or the OWA can be revised and extended with the IPOWA operator. Moreover, we can apply it in neural network theory, evolutionary computation, probabilistic reasoning and chaotic computing. 
- Decision Theory and Operational Research: decision theory is critically sustained on the use of a wide range of aggregations operators like the IPOWA operator.

- Business Administration: for example, we can apply it in strategic and financial management, accounting, marketing and human resource management.

- Economics and Politics: we can use it for developing more complete economic theories and economic decisions.

- Biology and Medicine: biostatistics can be revised with the IPOWA operator.

- Physics and Chemistry: physical and chemical statistics can be revised by using the IPOWA operator.

- Other sciences: many other applications could be developed in a lot of other sciences such as in psychology, sociology, geography and a wide range of disciplines in engineering.

In summary, any current or future research that uses either the IOWA or the PA can be revised and extended by using this new approach.

\subsection{Theoretical applications in statistics}

In the following, we implement the IPOWA operator in some key concepts in statistics (McClave, Sincich 2003). Note that these statistical concepts are very useful in an astonishingly wide range of disciplines. For example, we can revise the average and the variance of a population (discrete case) using the IPOWA operator. Note that the average (or the weighted average) should be replaced by the IPOWA operator, using Eq. (4). For the variance, we obtain the following formulation:

$$
\operatorname{Var-IPOWA}(X)=\sum_{j=1}^{n} \hat{p}_{j} D_{j},
$$

where $D_{j}$ is the $\left(x_{i}-\mu\right)^{2}$ value of the Var-IPOWA triplet $\left\langle u_{i}, \mu, x_{i}\right\rangle$ having the $j$ th largest $u_{i}$, $u_{i}$ is the order inducing variable, $x_{i}$ is the argument variable, $\mu$ is the average (in this case, the IPOWA operator), $w_{j} \in[0,1]$ and $\sum_{j=1}^{n} w_{j}=1$, each argument $\left(x_{i}-\mu\right)^{2}$ has an associated probability (PA) $p_{i}$ with $\sum_{i=1}^{n} p_{i}=1$ and $p_{i} \in[0,1], \hat{p}_{j}=\beta w_{j}+(1-\beta) p_{j}$ with $\beta \in[0,1]$ and $p_{j}$ is the probability (PA) $p_{i}$ ordered according to $D_{j}$, that is, according to the $j$ th largest $u_{i}$.

Note that Yager $(1996,2006)$ considered the use of the OWA operator in the variance. Once we have the variance, it is straightforward to obtain the standard deviation (SD) with the IPOWA operator.

The covariance can also be extended by using the IPOWA operator. In this case, we get the following:

$$
\operatorname{Cov}-\operatorname{IPOWA}(X, Y)=\sum_{j=1}^{n} \hat{p}_{j} K_{j},
$$

where $K_{j}$ is the $\left(x_{i}-\mu\right)\left(y_{i}-v\right)$ value of the Var-IPOWA triplet $\left\langle u_{i}, x_{i}, y_{i}\right\rangle$ having the $j$ th largest $u_{i}, u_{i}$ is the order inducing variable, $x_{i}$ is the argument variable of the first set of elements $X=\left\{x_{1}, \ldots, x_{n}\right\}$ and $y_{i}$ the argument variable of the second set of elements 
$Y=\left\{y_{1}, \ldots, y_{n}\right\}, \mu$ and $v$ are the average (in this case, the IPOWA operator) of the sets $X$ and $Y$ respectively, $w_{j} \in[0,1]$ and $\sum_{j=1}^{n} w_{j}=1$, each argument $\left(x_{i}-\mu\right)\left(y_{i}-v\right)$ has an associated probability (PA) $p_{i}$ with $\sum_{i=1}^{n} p_{i}=1$ and $p_{i} \in[0,1], \hat{p}_{j}=\beta w_{j}+(1-\beta) p_{j}$ with $\beta \in[0,1]$ and $p_{j}$ is the probability (PA) $p_{i}$ ordered according to $K_{j}$, that is, according to the $j$ th largest $u_{i}$.

From this formulation, we can analyze several measures of correlation, such as the Pearson coefficient (PC) with the IPOWA (PC - IPOWA). It is formulated as follows:

$$
P C-I P O W A=\frac{\operatorname{Cov}-\operatorname{IPOWA}(X, Y)}{\sqrt{\operatorname{Var}-\operatorname{IPOWA}(X) \times \operatorname{Var}-\operatorname{IPOWA}(Y)}} .
$$

The PC - IPOWA is 1 if there is an increasing linear relationship and -1 if there is a decreasing linear relationship. If the variables $X$ and $Y$ are independent, then the PC - IPOWA is 0 .

Furthermore, we can form a linear regression process using the IPOWA operator. To construct the linear regression model $y_{h}=\alpha+\beta x_{h}$, we calculate $\beta$ as follows:

$$
\hat{\beta}_{I P O W A}=\frac{\operatorname{Cov}-\operatorname{IPOW} A(X, Y)}{\operatorname{Var}-\operatorname{IPOW}(X)} .
$$

Next, we calculate the $\hat{\alpha}_{P O W A}$ value: $\hat{\alpha}_{I P O W A}=\bar{y}_{I P O W A}-\beta_{I P O W A} \bar{x}_{I P O W A}$, where $\bar{x}_{I P O W A}$ and $\bar{y}_{\text {IPOWA }}$ are the average of the sets $X$ and $Y$ calculated by using a IPOWA operator. Once we have $\hat{\alpha}_{I P O W A}$ and $\hat{\beta}_{I P O W A}$, we can construct the linear regression model with the IPOWA operator as follows:

$$
y_{h}=\hat{\alpha}_{I P O W A}+\hat{\beta}_{I P O W A} x_{h} .
$$

Note that other existing methods can be revised and extended using the IPOWA operator such as in descriptive statistics, inferential statistics, hypothesis testing, correlation and regression, as well as in other scientific areas. Note that when we replace the PA with the IPOWA, we are not deleting the PA from the analysis because it is included in the IPOWA operator.

\section{Decision-making with the IPOWA operator}

In this Section we present a new decision-making approach by using the IPOWA operator. First, we present some basic forms for decision-making. Next we analyze the decision-making approach with a multi-person analysis. Finally, we develop an illustrative example in strategic decision-making.

\subsection{Introduction}

In the literature, we find different methodologies for decision-making. For example, we can mention multiple criteria decision-making, group decision-making and game theory. When making decisions, the information may present different degrees of uncertainty. 
In general terms, it is assumed that we can distinguish between 3 forms of decisionmaking processes:

1) Decision-making under certainty: when we know the information that is going to happen in the future. In this case it is more or less easy to make a decision. Some common techniques in these problems are the use of linear programming approaches.

2) Decision-making under risk: when we know the possible outcomes but we do not know which of them is going to happen in the future. However, we can assess the information with probabilities. In this situation it is very common to use probabilistic decision-making techniques such as the expected value.

3) Decision-making under uncertainty: when we know the possible outcomes but we do not know which of them is going to occur in the future and we do not have any probabilistic information.

This general framework has been extended by a lot of authors in different ways. Some of them have focussed on the improvement of decision-making problems under certainty (Figueira et al. 2005), some others in risk problems such as the use of utility theory and some others in the understanding of the uncertainty.

However, it is interesting that these three general categories are not strictly independent and we can find a lot of partial situations that use two of them or even all three. The reason is that the complexity of our world has clearly shown that in order to properly assess real-world problems we have to assume that the information is very heterogeneous and it is not so easy to assess it. Thus, by adding more concepts and interpretation in the decision-making problems, we can introduce a lot of other types of decision-making methodologies.

For example, it is worth noting the use of imprecise information. In the literature, we find a wide range of models for dealing with imprecise information such as the use of interval numbers, fuzzy numbers, linguistic variables and multi-person techniques (Liu 2009, 2011a; Liu et al. 2011; Liu, Su 2010; Liu, Zhang 2010, 2011; Merigó, Casanovas 2010a, 2011a, 2011c; Merigó et al. 2010; Zhang, Liu 2010). Thus, if we focus on these techniques, we can develop a wide range of decision-making approaches. In Table 2 we present the methods that use the previous techniques.

Note that in all these situations we assume that we know partially the outcomes because we know more or less the results but we cannot provide precise results. Thus, we need other techniques to assess the information such as the use of interval numbers, fuzzy numbers, linguistic variables and multi-person techniques.

A further interesting issue to consider is the meaning of the set of arguments aggregated in the decision-making process because this may lead to different interpretations of the information. For example, we can aggregate the information that represents the results obtained according to the states of nature that may occur in the future, the different alternatives that we can select if one state of nature occurs, the different criteria that we can consider and so on. 
Table 2. Decision-making (DM) approaches

\begin{tabular}{|c|c|c|c|}
\hline & DM under certainty & DM under risk & DM - uncertainty \\
\hline Interval numbers & $\begin{array}{l}\text { Imprecise DM under } \\
\text { certainty }\end{array}$ & $\begin{array}{l}\text { Imprecise DM under } \\
\text { risk }\end{array}$ & $\begin{array}{c}\text { Imprecise DM under } \\
\text { uncertainty }\end{array}$ \\
\hline Fuzzy numbers & $\begin{array}{l}\text { Fuzzy DM under } \\
\text { certainty }\end{array}$ & Fuzzy DM under risk & $\begin{array}{l}\text { Fuzzy DM under } \\
\text { uncertainty }\end{array}$ \\
\hline Linguistic variables & $\begin{array}{l}\text { Linguistic DM under } \\
\text { certainty }\end{array}$ & $\begin{array}{l}\text { Linguistic DM under } \\
\text { risk }\end{array}$ & $\begin{array}{c}\text { Linguistic DM under } \\
\text { uncertainty }\end{array}$ \\
\hline $\begin{array}{l}\text { Multi-person } \\
\text { techniques }\end{array}$ & $\begin{array}{l}\text { Multi-person DM } \\
\text { under certainty }\end{array}$ & $\begin{array}{l}\text { Multi-person DM } \\
\text { under risk }\end{array}$ & $\begin{array}{l}\text { Multi-person DM } \\
\text { under uncertainty }\end{array}$ \\
\hline $\begin{array}{c}\text { Multi-person } \\
\text { techniques }+ \\
\text { Interval numbers }\end{array}$ & $\begin{array}{l}\text { Imprecise multi- } \\
\text { person DM under } \\
\text { certainty }\end{array}$ & $\begin{array}{l}\text { Imprecise multi- } \\
\text { person DM under risk }\end{array}$ & $\begin{array}{l}\text { Imprecise multi- } \\
\text { person DM under } \\
\text { uncertainty }\end{array}$ \\
\hline $\begin{array}{c}\text { Multi-person } \\
\text { techniques }+ \\
\text { Fuzzy numbers }\end{array}$ & $\begin{array}{l}\text { Fuzzy multi-person } \\
\text { DM under certainty }\end{array}$ & $\begin{array}{l}\text { Fuzzy multi-person } \\
\text { DM under risk }\end{array}$ & $\begin{array}{l}\text { Fuzzy multi-person } \\
\text { DM under uncertainty }\end{array}$ \\
\hline $\begin{array}{c}\text { Multi-person } \\
\text { techniques }+ \\
\text { Linguistic variables }\end{array}$ & $\begin{array}{l}\text { Linguistic multi- } \\
\text { person DM under } \\
\text { certainty }\end{array}$ & $\begin{array}{l}\text { Linguistic multi- } \\
\text { person DM under risk }\end{array}$ & $\begin{array}{l}\text { Linguistic multi- } \\
\text { person DM under } \\
\text { uncertainty }\end{array}$ \\
\hline
\end{tabular}

In decision-making problems it is very interesting to consider a set of arguments $a$ that depend on a set of states of nature $S$ and a set of alternatives $A$. This information can be represented in the following matrix shown in Table 3.

As we can see, we can aggregate the arguments in different ways. In general, we can summarize the problem in three types of decision-making methodologies.

Decision-making "ex-ante": when we aggregate the information according to an alternative selected and see the potential results depending on the states of nature that happen in the future. That is, select an action and see its potential results (aggregation of a row).

Table 3. Matrix with states of nature and alternatives

\begin{tabular}{ccccccccc}
\hline & $S_{1}$ & & $S_{i}$ & & $S_{n}$ & PA & OWA & IPOWA \\
\hline$A_{1}$ & $a_{11}$ & $\ldots$ & $a_{1 i}$ & $\ldots$ & $a_{1 n}$ & $R_{1}$ & $T_{1}$ & $U_{1}$ \\
\hline$\ldots$ & $\ldots$ & $\ldots$ & $\ldots$ & $\ldots$ & $\ldots$ & $\ldots$ & $\ldots$ & $\ldots$ \\
\hline$A_{\mathrm{h}}$ & $a_{h 1}$ & $\ldots$ & $a_{h i}$ & $\ldots$ & $a_{h n}$ & $R_{h}$ & $T_{h}$ & $U_{h}$ \\
\hline$\ldots$ & $\ldots$ & $\ldots$ & $\ldots$ & $\ldots$ & $\ldots$ & $\ldots$ & $\ldots$ & $\ldots$ \\
\hline$A_{\mathrm{k}}$ & $a_{k 1}$ & $\ldots$ & $a_{k i}$ & $\ldots$ & $a_{k n}$ & $R_{k}$ & $T_{k}$ & $U_{k}$ \\
\hline PA & $X_{1}$ & $\ldots$ & $X_{i}$ & $\ldots$ & $X_{n}$ & & & \\
\hline OWA & $Y_{1}$ & $\ldots$ & $Y_{i}$ & $\ldots$ & $Y_{n}$ & & & \\
\hline IPOWA & $Z_{1}$ & $\ldots$ & $Z_{i}$ & $\ldots$ & $Z_{n}$ & & & \\
\hline
\end{tabular}


Decision-making “ex-post": when we aggregate the arguments according to a state of nature that occurs and see how we can react. That is, assume that a state of nature happens and see how we can react (aggregation of a column).

Decision-making "ex-ante" and "ex-post": when we mix both cases in the same decision-making process.

With these three general frameworks, we could again consider a wide range of decision-making approaches by mixing these concepts with the previous ones. If we only consider problems with exact (or precise) information, we could consider the following decision-making approaches shown in Table 4.

Table 4. Decision-making approaches with precise information

\begin{tabular}{llcc}
\hline & DM under certainty & DM under risk & DM - uncertainty \\
\hline DM "ex-ante" & $\begin{array}{c}\text { DM under certainty } \\
\text { "ex-ante" }\end{array}$ & $\begin{array}{c}\text { DM under risk } \\
\text { "ex-ante" }\end{array}$ & $\begin{array}{c}\text { DM - uncertainty } \\
\text { "ex-ante" }\end{array}$ \\
\hline DM "ex-post" & DM under certainty & $\begin{array}{c}\text { DM under risk } \\
\text { "ex-post" }\end{array}$ & $\begin{array}{c}\text { DM - uncertainty } \\
\text { "ex-post" }\end{array}$ \\
\hline $\begin{array}{l}\text { DM "ex-ante" } \\
\text { and "ex-post" }\end{array}$ & $\begin{array}{c}\text { DM under certainty } \\
\text { "ex-ante" and "ex-post" }\end{array}$ & $\begin{array}{c}\text { DM under risk } \\
\text { "ex-ante" and "ex-post" }\end{array}$ & $\begin{array}{c}\text { DM - uncertainty } \\
\text { "ex-ante" and "ex-post" }\end{array}$ \\
\hline
\end{tabular}

This table can also be extended by using techniques that deals with uncertain environments that can not be assessed with exact (or precise) information. In Table 5 we present these decision-making approaches. Note that in each case we include decision-making under certainty, risk and uncertainty.

Table 5. Decision-making approaches without exact (or precise) information

\begin{tabular}{|c|c|c|c|}
\hline & DM “ex-ante" & DM “ex-post” & DM "ex-ante" and "ex-post" \\
\hline Interval numbers & $\begin{array}{l}\text { Imprecise DM } \\
\text { "ex-ante" }\end{array}$ & $\begin{array}{l}\text { Imprecise DM } \\
\text { "ex-post" }\end{array}$ & $\begin{array}{c}\text { Imprecise DM “ex-ante" - } \\
\text { "ex-post" }\end{array}$ \\
\hline Fuzzy numbers & $\begin{array}{l}\text { Fuzzy DM } \\
\text { "ex-ante" }\end{array}$ & $\begin{array}{l}\text { Fuzzy DM } \\
\text { "ex-post" }\end{array}$ & $\begin{array}{l}\text { Fuzzy DM “ex-ante” - } \\
\text { "ex-post" }\end{array}$ \\
\hline Linguistic variables & $\begin{array}{l}\text { Linguistic DM } \\
\text { "ex-ante" }\end{array}$ & $\begin{array}{l}\text { Linguistic DM } \\
\text { "ex-post" }\end{array}$ & $\begin{array}{l}\text { Linguistic DM “ex-ante" - } \\
\text { "ex-post" }\end{array}$ \\
\hline $\begin{array}{l}\text { Multi-person } \\
\text { techniques }\end{array}$ & $\begin{array}{l}\text { Multi-person DM } \\
\text { "ex-ante" }\end{array}$ & $\begin{array}{l}\text { Multi-person DM } \\
\text { "ex-post" }\end{array}$ & $\begin{array}{l}\text { Multi-person DM } \\
\text { "ex-ante" - "ex-post" }\end{array}$ \\
\hline $\begin{array}{c}\text { Multi-person } \\
\text { techniques }+ \text { Interval } \\
\text { numbers }\end{array}$ & $\begin{array}{c}\text { Imprecise } \\
\text { multi-person DM } \\
\text { "ex-ante" }\end{array}$ & $\begin{array}{c}\text { Imprecise } \\
\text { multi-person DM } \\
\text { "ex-post" }\end{array}$ & $\begin{array}{l}\text { Imprecise multi-person DM } \\
\text { "ex-ante" - "ex-post" }\end{array}$ \\
\hline $\begin{array}{c}\text { Multi-person } \\
\text { techniques + Fuzzy } \\
\text { numbers }\end{array}$ & $\begin{array}{l}\text { Fuzzy multi-person } \\
\text { DM "ex-ante" }\end{array}$ & $\begin{array}{l}\text { Fuzzy multi-person } \\
\text { DM “ex-post" }\end{array}$ & $\begin{array}{l}\text { Fuzzy multi-person DM } \\
\text { "ex-ante" - "ex-post" }\end{array}$ \\
\hline $\begin{array}{c}\text { Multi-person } \\
\text { techniques }+ \\
\text { Linguistic variables }\end{array}$ & $\begin{array}{c}\text { Linguistic } \\
\text { multi-person DM } \\
\text { "ex-ante" }\end{array}$ & $\begin{array}{c}\text { Linguistic } \\
\text { multi-person DM } \\
\text { "ex-post" }\end{array}$ & $\begin{array}{l}\text { Linguistic multi-person DM } \\
\text { "ex-ante" - "ex-post" }\end{array}$ \\
\hline
\end{tabular}


Note that most of the papers in the literature usually focus on decision-making problems "ex-ante". However, we believe that the use of decision-making problems "ex-post" is very relevant in order to appropriately deal with real-world decisions. For example, the usual management of a company or a country is conditioned both by "ex-ante" and "ex-post" decisions because both processes represent a usual activity in order to obtain the most efficient decisions.

All these approaches can be mixed because the decision-making process usually involves several sources of information so it is very common that each part is assessed with different techniques. Considering the new developments presented in this paper, we want to draw special attention to the use of decision-making problems under risk and under uncertainty in the same formulation. As we have mentioned before, decisionmaking under risk is usually assessed with probabilities and decision-making under uncertainty with the OWA operator. Therefore, with the introduction of the IPOWA operator, we can assess these two problems in the same formulation and considering the degree of importance of each concept in the analysis. Thus, with the IPOWA operator we can formulate a new decision-making approach:

- Decision-making under risk and uncertainty:

- If $\beta=1$, we get decision-making under uncertainty.

- If $\beta=0$, we get decision-making under risk.

A further interesting issue when dealing with the IPOWA operator is that we can use subjective and objective probabilities in the analysis. Note that an objective probability is formed with the use of objective information based on experiments, historical data and related techniques. On the other hand, a subjective probability is constructed with the use of subjective information based on the intuition, personal opinions and related techniques. Thus, we can formulate the following decision-making approaches:

- Decision-making under subjective risk and uncertainty:

- If $\beta=0$, we get decision-making under subjective risk.

- Decision-making under objective risk and uncertainty:

- If $\beta=0$, we get decision-making under objective risk.

Moreover, we can also extend all the previous decision-making approaches presented in Tables 2, 4 and 5 to the case with subjective and objective risk.

Note that there are a lot of other methods and techniques that deal with decision-making problems. Therefore, we can construct a lot of other decision-making approaches as it has been constructed in the previous tables. However, we believe that we have provided an appropriate general overview according to the objectives of the paper.

\subsection{Multi-person decision-making process}

In the following, we are going to develop a multi-person decision-making process with the IPOWA operator in strategic management. The use of a multi-person analysis provides a more complete representation of the problem because it is based on the opinion of several people. Therefore, we can aggregate the opinion of different people to obtain a representative view of the problem. In strategic management this is very common 
because usually the companies require the use of the opinion of several experts in order to form the most efficient decisions. An example of this approach is the decision-making process of the board of directors of the company. Although the opinion of some persons is usually more relevant than the rest, there are a lot of persons that may condition the final decision.

Note that many other group decision-making models have been discussed in the literature (Merigó, Casanovas 2011b; Wei et al. 2010; Xu 2010; Zhou, Chen 2011). However, in this paper we focus on a multi-person decision-making problem under risk and uncertainty "ex-ante".

Step 1: Let $A=\left\{A_{1}, A_{2}, \ldots, A_{m}\right\}$ be a set of finite alternatives, $S=\left\{S_{1}, S_{2}, \ldots, S_{n}\right\}$, a set of finite states of nature (or attributes), forming the payoff matrix $\left(a_{h i}\right)_{m \times n}$. Let $E=\left\{e_{1}, e_{2}, \ldots, e_{q}\right\}$ be a finite set of decision-makers. Let $X=\left(x_{1}, x_{2}, \ldots, x_{q}\right)$ be the weighting vector of the decision-makers such that $\sum_{k=1}^{q} x_{k}=1$ and $x_{k} \in[0,1]$. Each decision-maker provides his own payoff matrix $\left(a_{h i}{ }^{(k)}\right)_{m \times n}$.

Step 2: Calculate the weighting vector $\hat{P}=\beta \times W+(1-\beta) \times P$ to be used in the IPOWA aggregation. Note that $P=\left(p_{1}, p_{2}, \ldots, p_{n}\right)$ such that $\sum_{i=1}^{n} p_{i}=1$ and $p_{i} \in[0,1]$ and $W=\left(w_{1}, w_{2}, \ldots, w_{n}\right)$ such that $\sum_{j=1}^{n} w_{j}=1$ and $w_{j} \in[0,1]$.

Step 3: Use the weighted average to aggregate the information of the decision-makers $E$ using the weighting vector $X$. The result is the collective payoff matrix $\left(a_{h i}\right)_{m \times n}$. Thus, $a_{h i}=\sum_{k=1}^{q} x_{k} a_{h i}^{k}$.

Step 4: Calculate the aggregated results using the IPOWA operator (Eq. (4) or (5)). Consider different families of IPOWA operators as described in Section 3.

Step 5: Make decisions according to the results obtained in the previous steps. Select the alternative(s) that provides the best result(s). Moreover, establish a ranking of the alternatives from the most to the least-preferred alternative.

This aggregation process can be summarized using the following aggregation operator that we call the multi-person - IPOWA (MP-IPOWA) operator.

Definition 7: A MP-IPOWA operator is a mapping MP-IPOWA: $R^{n} \times R^{q} \rightarrow R$ that has a weighting vector $X$ of dimension $q$ with $\sum_{k=1}^{q} x_{k}=1$ and $x_{k} \in[0,1]$ and a weighting vector $W$ of dimension $n$ with $\sum_{j=1}^{n} w_{j}=1$ and $w_{j} \in[0,1]$, such that:

$$
\text { MP-IPOWA }\left(\left\langle u_{1},\left(a_{1}{ }^{1}, \ldots, a_{1}{ }^{p}\right)\right\rangle, \ldots,\left\langle u_{n},\left(a_{n}{ }^{1}, \ldots, a_{n}{ }^{p}\right)\right\rangle\right)=\sum_{j=1}^{n} \hat{p}_{j} b_{j},
$$

where $b_{j}$ is the $a_{i}$ value of the IPOWA pair $\left\langle u_{i}, a_{i}\right\rangle$ having the $j$ th largest $u_{i}, u_{i}$ is the order inducing variable, each argument $a_{i}$ has an associated probability $p_{i}$ with $\sum_{i=1}^{n} p_{i}=1$ and $p_{i} \in[0,1], \hat{p}_{j}=\beta w_{j}+(1-\beta) p_{j}$ with $\beta \in[0,1]$ and $p_{j}$ is the probability $p_{i}$ ordered according to $b_{j}$, that is, according to the $j$ th largest $u_{i}, a_{i}=\sum_{k=1}^{q} x_{k} a_{i}^{k}, a_{i}^{k}$ is the argument variable provided by each person.

Note that the MP-IPOWA operator has similar properties than the IPOWA operator, such as the distinction between descending and ascending orders, and so on. 
The MP-IPOWA operator includes a wide range of particular cases following the methodology explained in Section 3. Thus, it includes:

- The multi-person - PA (MP-PA) operator.

- The multi-person - OWA (MP-OWA) operator.

- The multi-person - IOWA (MP-IOWA) operator.

- The multi-person - arithmetic mean (MP-AM) operator.

- The multi-person - arithmetic-PA (MP-AUPA) operator.

- The multi-person - arithmetic-IOWA (MP-AIOWA) operator.

It is possible to consider more complex situations by using different types of aggregation operators to aggregate the experts opinions instead of the weighted average used in Definition 7.

\subsection{Application in strategic decision-making}

In the following, we present a numerical example of the new approach in a multiperson decision-making problem regarding the selection of strategies. Note that other decision-making applications could be developed in other areas such as construction management (Antuchevičienè et al. 2010), software supported negotiations, real estate investment projects, strategic planning in public institutions and selection of project managers.

Step 1: Assume a company that operates in Spain and Portugal is planning the general strategy for the next year and considers six general strategies to follow:

$-A_{1}=$ Expand to the French market.

$-A_{2}=$ Expand to the Italian market.

$-A_{3}=$ Expand to the German market.

$-A_{4}=$ Expand to the British market.

$-A_{5}=$ Expand to the North African market.

$-A_{6}=$ Do not develop any expansion.

To evaluate these strategies, the group of experts of the company considers that the key factor is the economic situation of the world economy for the next period. They consider 8 possible states of nature that could happen in the future:

$-S_{1}=$ Very bad economic situation.

$-S_{2}=$ Bad economic situation.

$-S_{3}=$ Regular - bad economic situation.

$-S_{4}=$ Regular economic situation.

$-S_{5}=$ Regular - good economic situation.

$-S_{6}=$ Good economic situation.

$-S_{7}=$ Very good economic situation.

- $S_{8}=$ Extremely good economic situation. 
The company has 4 experts that are allowed to make decisions with the following weights that represent the importance that each expert has in the analysis: $X=(0.2,0.2$, $0.3,0.3)$. Each expert provides his own opinion regarding the benefits of the strategies according to the state of nature $S_{i}$ and the alternative $A_{k}$ that the company may choose. The results are presented in Tables 6, 7, 8 and 9.

Table 6. Expert 1

\begin{tabular}{ccccccccc}
\hline & $S_{1}$ & $S_{2}$ & $S_{3}$ & $S_{4}$ & $S_{5}$ & $S_{6}$ & $S_{7}$ & $S_{8}$ \\
\hline$A_{1}$ & 60 & 80 & 30 & 70 & 50 & 60 & 90 & 20 \\
\hline$A_{2}$ & 30 & 40 & 60 & 70 & 80 & 30 & 40 & 50 \\
\hline$A_{3}$ & 50 & 70 & 20 & 50 & 70 & 60 & 80 & 30 \\
\hline$A_{4}$ & 60 & 70 & 10 & 80 & 60 & 30 & 50 & 20 \\
\hline$A_{5}$ & 90 & 20 & 70 & 10 & 50 & 40 & 60 & 30 \\
\hline$A_{6}$ & 30 & 40 & 50 & 60 & 70 & 60 & 50 & 40 \\
\hline
\end{tabular}

Table 7. Expert 2

\begin{tabular}{ccccccccc}
\hline & $S_{1}$ & $S_{2}$ & $S_{3}$ & $S_{4}$ & $S_{5}$ & $S_{6}$ & $S_{7}$ & $S_{8}$ \\
\hline$A_{1}$ & 50 & 60 & 30 & 60 & 40 & 70 & 80 & 30 \\
\hline$A_{2}$ & 20 & 40 & 60 & 70 & 80 & 50 & 40 & 60 \\
\hline$A_{3}$ & 30 & 40 & 20 & 80 & 70 & 50 & 80 & 20 \\
\hline$A_{4}$ & 40 & 50 & 60 & 60 & 60 & 70 & 70 & 70 \\
\hline$A_{5}$ & 20 & 10 & 20 & 30 & 50 & 50 & 60 & 90 \\
\hline$A_{6}$ & 30 & 40 & 80 & 60 & 70 & 80 & 20 & 30 \\
\hline
\end{tabular}

Table 8. Expert 3

\begin{tabular}{lllllllll}
\hline & $S_{1}$ & $S_{2}$ & $S_{3}$ & $S_{4}$ & $S_{5}$ & $S_{6}$ & $S_{7}$ & $S_{8}$ \\
\hline$A_{1}$ & 30 & 70 & 40 & 60 & 70 & 60 & 50 & 60 \\
\hline$A_{2}$ & 20 & 40 & 60 & 70 & 90 & 80 & 40 & 30 \\
\hline$A_{3}$ & 10 & 10 & 20 & 40 & 70 & 70 & 80 & 80 \\
\hline$A_{4}$ & 30 & 60 & 40 & 70 & 60 & 80 & 60 & 60 \\
\hline$A_{5}$ & 40 & 50 & 60 & 70 & 50 & 60 & 60 & 70 \\
\hline$A_{6}$ & 30 & 40 & 50 & 60 & 70 & 80 & 80 & 80 \\
\hline
\end{tabular}

Table 9. Expert 4

\begin{tabular}{ccccccccc}
\hline & $S_{1}$ & $S_{2}$ & $S_{3}$ & $S_{4}$ & $S_{5}$ & $S_{6}$ & $S_{7}$ & $S_{8}$ \\
\hline$A_{1}$ & 40 & 30 & 30 & 50 & 60 & 70 & 40 & 70 \\
\hline$A_{2}$ & 20 & 40 & 70 & 80 & 90 & 60 & 40 & 20 \\
\hline$A_{3}$ & 20 & 20 & 20 & 50 & 70 & 80 & 80 & 80 \\
\hline$A_{4}$ & 30 & 40 & 50 & 60 & 60 & 70 & 70 & 80 \\
\hline$A_{5}$ & 40 & 50 & 60 & 70 & 50 & 60 & 60 & 60 \\
\hline$A_{6}$ & 30 & 40 & 40 & 60 & 70 & 70 & 70 & 70 \\
\hline
\end{tabular}


In this example, we assume the following order inducing variables $U=(2,3,9,8,7$, $6,5,4)$. The experts assume the following weighting vector for the IOWA: $W=(0.1$, $0.1,0.1,0.1,0.1,0.1,0.2,0.2)$; for the probability: $P=(0.1,0.1,0.1,0.2,0.2,0.1,0.1$, 0.1 ); and $\beta=30 \%$. In order to assess this problem, first, we aggregate the information of the four experts into one collective matrix that represents the aggregated opinion. Note that each expert gives its real opinion believing that they might be wrong and thus, they are open to hear the opinion of the other experts. Therefore, we assume that there is no attempt from the experts to manipulate the results in order to obtain a final decision that it is closer to the individual opinion of one of them. However, according to the weighting vector $X$, we see that the opinion of the experts 3 and 4 is more relevant. The results are shown in Table 10.

Table 10. Collective results

\begin{tabular}{lllllllll}
\hline & $S_{1}$ & $S_{2}$ & $S_{3}$ & $S_{4}$ & $S_{5}$ & $S_{6}$ & $S_{7}$ & $S_{8}$ \\
\hline$A_{1}$ & 43 & 58 & 33 & 59 & 57 & 65 & 61 & 49 \\
\hline$A_{2}$ & 22 & 40 & 63 & 73 & 86 & 58 & 40 & 37 \\
\hline$A_{3}$ & 25 & 31 & 20 & 53 & 70 & 67 & 80 & 58 \\
\hline$A_{4}$ & 38 & 54 & 41 & 67 & 60 & 65 & 63 & 60 \\
\hline$A_{5}$ & 46 & 36 & 54 & 70 & 50 & 54 & 60 & 63 \\
\hline$A_{6}$ & 30 & 40 & 53 & 60 & 70 & 73 & 59 & 59 \\
\hline
\end{tabular}

Next, we can aggregate the expected results for each state of nature in order to make a decision by using Eq. (5). In Table 11, we present the results obtained by using different types of IPOWA operators.

Table 11. Aggregated results

\begin{tabular}{ccccccc}
\hline & Max-PA & Min-PA & AM & PA & IOWA & IPOWA \\
\hline$A_{1}$ & 55.37 & 47.77 & 53.12 & 54.1 & 52.6 & 53.65 \\
\hline$A_{2}$ & 66.26 & 47.06 & 52.37 & 57.8 & 48.1 & 54.89 \\
\hline$A_{3}$ & 60.89 & 42.89 & 50.5 & 52.7 & 46 & 50.69 \\
\hline$A_{4}$ & 60.35 & 51.65 & 56 & 57.5 & 54 & 56.45 \\
\hline$A_{5}$ & 59.71 & 49.51 & 54.12 & 55.3 & 51.5 & 54.16 \\
\hline$A_{6}$ & 62.08 & 49.18 & 55.5 & 57.4 & 51.4 & 55.6 \\
\hline
\end{tabular}

Moreover, it is possible to establish a ranking of the alternatives by looking to the results obtained in Table 11. In Table 12 we present these results. Note that the first alternative in each ordering is the optimal choice and $\}$ means "preferred to".

Table 12. Ranking of the strategies

\begin{tabular}{cccc}
\hline & Ordering & Ordering \\
\hline Max-PA & $\left.\left.\left.\left.\left.A_{2}\right\} A_{6}\right\} A_{3}\right\} A_{4}\right\} A_{5}\right\} A_{1}$ & PA & $\left.\left.\left.\left.\left.A_{2}\right\} A_{4}\right\} A_{6}\right\} A_{5}\right\} A_{1}\right\} A_{3}$ \\
\hline Min-PA & $\left.\left.\left.\left.\left.A_{4}\right\} A_{5}\right\} A_{6}\right\} A_{1}\right\} A_{2}\right\} A_{3}$ & IOWA & $\left.\left.\left.\left.\left.A_{4}\right\} A_{1}\right\} A_{5}\right\} A_{6}\right\} A_{2}\right\} A_{3}$ \\
\hline AM & $\left.\left.\left.\left.\left.A_{4}\right\} A_{6}\right\} A_{5}\right\} A_{1}\right\} A_{2}\right\} A_{3}$ & IPOWA & $\left.\left.\left.\left.\left.A_{4}\right\} A_{6}\right\} A_{2}\right\} A_{5}\right\} A_{1}\right\} A_{3}$ \\
\hline
\end{tabular}


As we can see, each particular type of IPOWA operator may lead to different results and decisions. The main idea behind this issue is that the decision-maker gets a complete view of the decision process so he knows different scenarios that may occur and select the one that it is in closest accordance with his interests. However, it is worth noting that the decision is affected by risk and uncertainty. Therefore, we do not know if the alternative selected by the decision-maker is the optimal one because we do not know what is going to happen in the future. However, we know that it is the most appropriate decision according to his attitudinal character.

By looking to the example, it seems that $A_{4}$ is the optimal choice although $A_{2}$ could also be selected according to the classical probabilistic aggregation.

\section{Conclusions}

We have introduced a new approach for dealing with risk and uncertain environments. For doing so, we have presented the IPOWA operator. It is an aggregation operator that provides a parameterized family of aggregation operators between the minimum and the maximum. Moreover, it unifies the probability and the IOWA operator in the same formulation and considering the degree of importance of each concept in the aggregation. Furthermore, it uses order inducing variables in order to assess complex reordering processes in the aggregation that represent complex attitudinal characters that may include psychological and personal factors in the analysis. We have studied some of its main properties and we have seen that it includes a wide range of particular cases including the probabilistic aggregation (expected value), the OWA operator, the IOWA operator, the arithmetic mean, the probabilistic maximum and the probabilistic minimum.

We have seen that the applicability of this approach is very broad because all the previous studies that use the probability or the OWA operator can be revised and extended with this new model. We have analysed some basic applications in statistics including the use of the IPOWA operator in the variance, in the covariance, in the Pearson coefficient and in a simple linear regression model.

We have focussed on an application in a decision-making model in strategic management. For doing so, we have first reviewed several decision-making approaches that could be used in the analysis including some innovative perspectives like the distinction between "ex-ante" and "ex-post" decisions. We have seen that the use of the IPOWA operator permits to unify decision-making models under risk and under uncertainty in the same formulation and in a flexible way because we can consider the degree of importance of each case in the analysis.

We have developed the decision-making application by using a multi-person analysis that permits to consider the opinion of several persons in the analysis. Thus, we have obtained a new aggregation operator called the MP-IPOWA operator. We have seen that it accomplishes similar properties than the IPOWA operator and a wide range of particular cases including the MP-PA, the MP-IOWA and the MP-AM. The use of this approach in strategic management has shown how we can deal with environments affected with both risk and uncertain factors and how we can provide the decision-maker with the most efficient decision. 
In future research, we expect to develop more general extensions of the IPOWA operator by using other representations of the information such as the use of interval numbers, fuzzy numbers and linguistic variables. We will also develop further generalizations by using distance measures, generalized aggregation operators and unified aggregation operators. Furthermore, we will also consider other applications giving special attention to decision theory and statistics.

\section{Acknowledgements}

We would like to thank the anonymous reviewers for valuable comments that have improved the quality of the paper. Support from the University of Barcelona through the project 099311 and the European Commission (PIEF-GA-2011-300062) is gratefully acknowledged.

\section{References}

Antuchevičienė, J.; Zavadskas, E. K.; Zakarevičius, A. 2010. Multiple criteria construction management decisions considering relations between criteria, Technological and Economic Development of Economy 16(1): 109-125. http://dx.doi.org/10.3846/tede.2010.07

Beliakov, G.; Pradera, A.; Calvo, T. 2007. Aggregation functions: a guide for practitioners. Berlin: Springer-Verlag.

Belles-Sampera, J.; Merigó, J. M.; Guillén, M.; Santolino, M. 2013. The connection between distortion risk measures and ordered weighted averaging operators, Insurance: Mathematics and Economics 52(2): 411-420. http://dx.doi.org/10.1016/j.insmatheco.2013.02.008

Chang, K. H.; Wen, T. C. 2010. A novel efficient approach for DFMEA combining 2-tuple and the OWA operator, Expert Systems with Applications 37(3): 2362-2370.

http://dx.doi.org/10.1016/j.eswa.2009.07.026

Engemann, K. J.; Filev, D. P.; Yager, R. R. 1996. Modelling decision-making using immediate probabilities, International Journal of General Systems 24(3): 281-294.

http://dx.doi.org/10.1080/03081079608945123

Figueira, J.; Greco, S.; Ehrgott, M. 2005. Multiple criteria decision analysis: state of the art surveys. Boston: Springer.

Liu, P. D. 2009. Multi-attribute decision-making method research based on interval vague set and TOPSIS method, Technological and Economic Development of Economy 15(3): 453-463. http://dx.doi.org/10.3846/1392-8619.2009.15.453-463

Liu, P. D. 2011a. A weighted aggregation operators multi-attribute group decision making method based on interval-valued trapezoidal fuzzy numbers, Expert Systems with Applications 38(2): 1053-1060. http://dx.doi.org/10.1016/j.eswa.2010.07.144

Liu, P. D.; Zhang, X. 2011. Investigation into evaluation of agriculture informatization level based on two-tuple, Technological and Economic Development of Economy 17(1): 74-86. http://dx.doi.org/10.3846/13928619.2011.554007

Luce, R. D.; Raiffa, H. 1989. Games and decisions. New York: Dover Publications.

McClave, J. T.; Sincich, T. 2003. Statistics. $9^{\text {th }}$ ed. Upper Saddle River, New Jersey: Prentice Hall. Merigó, J. M. 2010. Fuzzy decision making with immediate probabilities, Computers \& Industrial Engineering 58(4): 651-657. http://dx.doi.org/10.1016/j.cie.2010.01.007 
Merigó, J. M. 2012. Probabilities in the OWA operator, Expert Systems with Applications 39(13): 11456-11467. http://dx.doi.org/10.1016/j.eswa.2012.04.010

Merigó, J. M.; Casanovas, M. 2009. Induced aggregation operators in decision making with Dempster-Shafer belief structure, International Journal of Intelligent Systems 24(8): 934-954. http://dx.doi.org/10.1002/int.20368

Merigó, J. M.; Casanovas, M. 2010a. Fuzzy generalized hybrid aggregation operators and its application in decision making, International Journal of Fuzzy Systems 12(1): 15-24.

Merigó, J. M.; Casanovas, M. 2010b. Induced and heavy aggregation operators with distance measures, Journal of Systems Engineering and Electronics 21(3): 431-439.

Merigó, J. M.; Casanovas, M. 2011a. The uncertain induced quasi-arithmetic OWA operator, International Journal of Intelligent Systems 26(1): 1-24. http://dx.doi.org/10.1002/int.20444

Merigó, J. M.; Casanovas, M. 2011b. Decision making with distance measures and induced aggregation operators, Computers \& Industrial Engineering 60(1): 66-76.

http://dx.doi.org/10.1016/j.cie.2010.09.017

Merigó, J. M.; Casanovas, M. 2011c. Induced and uncertain heavy OWA operators, Computers \& Industrial Engineering 60(1): 106-116. http://dx.doi.org/10.1016/j.cie.2010.10.005

Merigó, J. M.; Casanovas, M.; Zeng, S. Z. 2014. Distance measures with heavy aggregation operators, Applied Mathematical Modelling 38(13): 3142-153.

http://dx.doi.org/10.1016/j.apm.2013.11.036

Merigó, J. M.; Engemann, K. J.; Palacios-Marqués, D. 2013. Decision making with DempsterShafer theory and the OWAWA operator, Technological and Economic Development of Economy 19(S1): S194-S212. http://dx.doi.org/10.3846/20294913.2013.869517

Merigó, J. M.; Gil-Lafuente, A. M. 2009. The induced generalized OWA operator, Information Sciences 179(6): 729-741. http://dx.doi.org/10.1016/j.ins.2008.11.013

Merigó, J. M.; Gil-Lafuente, A. M. 2010. New decision making techniques and their application in the selection of financial products, Information Sciences 180(11): 2085-2094.

http://dx.doi.org/10.1016/j.ins.2010.01.028

Merigó, J. M.; Gil-Lafuente, A. M. 2013. Induced 2-tuple linguistic generalized aggregation operators and their application in decision-making, Information Sciences 236: 1-16.

http://dx.doi.org/10.1016/j.ins.2013.02.039

Merigó, J. M.; Wei, G. W. 2011. Probabilistic aggregation operators and their application in uncertain multi-person decision making, Technological and Economic Development of Economy 17(2): 335-351. http://dx.doi.org/10.3846/20294913.2011.584961

Torra, V. 1997. The weighted OWA operator, International Journal of Intelligent Systems 12(2): 153-166. http://dx.doi.org/10.1002/(SICI)1098-111X(199702)12:2<153::AID-INT3>3.0.CO;2-P

Wei, G. W. 2010a. A method for multiple attribute group decision making based on the ET-WG and ET-OWG operators with 2-tuple linguistic information, Expert Systems with Aplications 37(12): 7895-7900. http://dx.doi.org/10.1016/j.eswa.2010.04.047

Wei, G. W. 2010b. Some induced geometric aggregation operators with intuitionistic fuzzy information and their application to group decision making, Applied Soft Computing 10(1): 423-431. http://dx.doi.org/10.1016/j.asoc.2009.08.009

Wei, G. W. 2010c. FIOWHM operator and its application to group decision making, Expert Systems with Applications 38(4): 2984-2989. http://dx.doi.org/10.1016/j.eswa.2010.08.087

Wei, G. W.; Zhao, X.; Lin, R. 2010. Some induced aggregating operators with fuzzy number intuitionistic fuzzy information and their applications to group decision making, International Journal of Computational Intelligence Systems 3(1): 84-95. http://dx.doi.org/10.2991/ijcis.2010.3.1.8 
Xu, Z. S. 2010. A deviation-based approach to intuitionistic fuzzy multiple attribute group decision making, Group Decision and Negotiation 19(1): 57-76.

http://dx.doi.org/10.1007/s10726-009-9164-Z

$\mathrm{Xu}, \mathrm{Z}$. S.; Da, Q. L. 2003. An overview of operators for aggregating information, International Journal of Intelligent Systems 18(9): 953-969. http://dx.doi.org/10.1002/int.10127

Yager, R. R. 1988. On ordered weighted averaging aggregation operators in multi-criteria decision making, IEEE Transactions on Systems, Man and Cybernetics B 18(1): 183-190.

http://dx.doi.org/10.1109/21.87068

Yager, R. R. 1992. Decision making under Dempster-Shafer uncertainties, International Journal of General Systems 20(3): 233-245. http://dx.doi.org/10.1080/03081079208945033

Yager, R. R. 1993. Families of OWA operators, Fuzzy Sets and Systems 59(2): 125-148. http://dx.doi.org/10.1016/0165-0114(93)90194-M

Yager, R. R. 1996. On the inclusion of variance in decision making under uncertainty, International Journal of Uncertainty, Fuzziness and Knowledge-Based Systems 4(5): 401-419. http://dx.doi.org/10.1142/S0218488596000238

Yager, R. R. 1999. Including decision attitude in probabilistic decision making, International Journal of Approximate Reasoning 21(1): 1-21. http://dx.doi.org/10.1016/S0888-613X(99)00002-X

Yager, R. R. 2003. Induced aggregation operators, Fuzzy Sets and Systems 137(1): 59-69.

http://dx.doi.org/10.1016/S0165-0114(02)00432-3

Yager, R. R. 2006. Generalizing variance to allow the inclusion of decision attitude in decision making under uncertainty, International Journal of Approximate Reasoning 42(3): 137-158. http://dx.doi.org/10.1016/j.ijar.2005.09.001

Yager, R. R. 2009. Weighted maximum entropy OWA aggregation with applications to decision making under risk, IEEE Transactions on Systems, Man and Cybernetics A 39(3): 555-564. http://dx.doi.org/10.1109/TSMCA.2009.2014535

Yager, R. R.; Engemann, K. J.; Filev, D. P. 1995. On the concept of immediate probabilities, International Journal of Intelligent Systems 10(4): 373-397. http://dx.doi.org/10.1002/int.4550100403 Yager, R. R.; Filev, D. P. 1999. Induced ordered weighted averaging operators, IEEE Transactions on Systems, Man and Cybernetics B 29(1): 141-150. http://dx.doi.org/10.1109/3477.752789

Yager, R. R.; Kacprzyk, J. 1997. The ordered weighted averaging operators: theory and applications. Norwell, MA: Kluwer Academic Publishers.

Yager, R. R.; Kacprzyk, J; Beliakov, G. 2011. Recent developments on the ordered weighted averaging operators: theory and practice. Berlin: Springer-Verlag.

Zavadskas, E. K.; Turskis, Z. 2010. A new additive ratio assessment (ARAS) method in multicriteria decision-making, Technological and Economic Development of Economy 16(2): 159-172. http://dx.doi.org/10.3846/tede.2010.10

Zavadskas, E. K.; Turskis, Z.; Ustinovichius, L.; Shevchenko, G. 2010. Attributes weights determining peculiarities in multiple attribute decision making methods, Inzinerine Ekonomika Engineering Economics 21(1): 32-43.

Zeng, S. Z.; Merigó, J. M.; Su, W. H. 2013. The uncertain probabilistic OWA distance operator and its application in group decision making, Applied Mathematical Modelling 37(9): 6266-6275. http://dx.doi.org/10.1016/j.apm.2013.01.022

Zeng, S. Z.; Su, W. H. 2012. Linguistic induced generalized aggregation distance operators and their application to decision making, Economic Computation and Economic Cybernetics Studies and Research 46(2): 155-172. 
Zhang, X.; Liu, P. D. 2010. Method for aggregating triangular fuzzy intuitionistic fuzzy information and its application to decision making, Technological and Economic Development of Economy 16(2): 280-290. http://dx.doi.org/10.3846/tede.2010.18

Zhao, H.; Xu, Z. S.; Ni, M.; Liu, S. 2010. Generalized aggregation operators for intuitionistic fuzzy sets, International Journal of Intelligent Systems 25(1): 1-30.

http://dx.doi.org/10.1002/int.20386

Zhou, L. G.; Chen, H. Y. 2010. Generalized ordered weighted logarithm aggregation operators and their applications to group decision making, International Journal of Intelligent Systems 25(7): 683-707. http://dx.doi.org/10.1002/int.20419

Zhou, L. G.; Chen, H. Y. 2011. A generalization of the power aggregation operators for linguistic environment and its application in group decision making, Knowledge-Based Systems 26(1): 216-224. http://dx.doi.org/10.1016/j.knosys.2011.08.004

Zhou, L. G.; Chen, H. Y.; Merigó, J. M.; Gil-Lafuente, A. M. 2012. Uncertain generalized aggregation operators, Expert Systems with Applications 39(1): 1105-1117.

http://dx.doi.org/10.1016/j.eswa.2011.07.110

José M. MERIGÓ has a MSc and a PhD degree in Business Administration from University of Barcelona, Spain. His $\mathrm{PhD}$ received the Extraordinary Award from the University of Barcelona. $\mathrm{He}$ also holds a Bachelor Degree in Economics and a Master in European Business Administration and Business Law from Lund University, Sweden. He is an Assistant Professor in the Department of Business Administration at the University of Barcelona. He has published more than 200 papers in journals, books and conference proceedings including journals such as Information Sciences, International Journal of Intelligent Systems, Technological and Economic Development of Economy, Expert Systems with Applications, Computers \& Industrial Engineering, International Journal of Uncertainty, Fuzziness and Knowledge-Based Systems, Cybernetics \& Systems, International Journal of Fuzzy Systems. He has published 4 books including one edited with World Scientific "Computational Intelligence in Business and Economics". He is on the editorial board of several journals including the Journal of Advanced Research on Fuzzy and Uncertain Systems and the ISTP Transactions of Systems \& Cybernetics. He has participated in several scientific committees and as a reviewer in a wide range of journals. He is currently interested in Aggregation Operators, Decision Making and Uncertainty. 